\title{
Correction to: Effects of Collagen Crosslink Augmentation on Mechanism of Compressive Load Sharing in Intervertebral Discs
}

\author{
Thomas P. Hedman ${ }^{1} \cdot$ Weng-Pin Chen ${ }^{2} \cdot$ Leou-Chyr Lin ${ }^{3} \cdot$ Hsiu-Jen Lin ${ }^{2} \cdot$ Shih-Youeng Chuang 3,4
}

Published online: 24 August 2018

(c) The Author(s) 2018, Corrected Publication August 2018

\section{Correction to: J. Med. Biol. Eng. (2017) 37:94-101 https://doi.org/10.1007/s40846-016-0207-z}

The article "Effects of Collagen Crosslink Augmentation on Mechanism of Compressive Load Sharing in Intervertebral Discs", written by Thomas P. Hedman, Weng-Pin Chen, Leou-Chyr Lin, Hsiu-Jen Lin, Shih-Youeng Chuang was originally published electronically on the publisher's internet portal (currently SpringerLink) on 19 January 2017 without open access.

After publication in volume [37], issue [1], page [94-101] the authors decided to opt for Open Choice and to make the article an open access publication. Therefore, the copyright of the article has been changed to (C) The Author(s) 2018 and the article is forthwith distributed under the terms of the Creative Commons Attribution 4.0 International License (http://creativecommons.org/licenses/by/4.0/), which permits use, duplication, adaptation, distribution and reproduction in any medium or format, as long as you give appropriate credit to the original author(s) and the source, provide a link to the Creative Commons license, and indicate if changes were made.
The original article can be found online at https://doi.org/10.1007/ s40846-016-0207-z.

Shih-Youeng Chuang

shihyouc@hotmail.com

1 Department of Biomedical Engineering, University of Kentucky, Lexington, KY, USA

2 Department of Mechanical Engineering, National Taipei University of Technology, Taipei, Taiwan, ROC

3 Department of Orthopaedic Surgery, Tri-Service General Hospital, National Defense Medical Center, Taipei, Taiwan, ROC

4 Department of Orthopaedic Surgery, Kang-Ning General Hospital, No.26, Ln. 420, Sec. 5, Chenggong Rd., Neihu Dist., Taipei, Taiwan, ROC 